\title{
Memória nos trilhos: o patrimônio ferroviário e sua contribuição às práticas preservacionistas brasileiras na década de 1980
}

Memory on the rails: railway heritage and its contribution to Brazilian preventive practices in the 1980s

https://doi.org/10.1590/1982-02672020v28d2e27

\section{LUCINA FERREIRA MATOS 1}

https://orcid.org/0000-0001-5997-0712

Fundação Oswaldo Cruz / Rio de Janeiro, RJ, Brasil

RESUMO: Este artigo contém reflexões sobre o processo de valorização e reconhecimento do patrimônio cultural ferroviário, emergente ao longo dos anos de 1980, interpretando-o como elemento importante na estruturação do direito à cultura, à identidade e ao patrimônio nacional. $\bigcirc$ texto apresentado está embasado em pesquisas sobre o passado ferroviário e seu deslocamento de objeto de ações restritas a comemorações festivas para a sua encampação como política pública. Apresenta, de modo sucinto, a análise do Programa de Preservação do Patrimônio Histórico (Preserve) e das associações de preservação ferroviárias (APFs). Duas iniciativas contemporâneas que auxiliaram na consolidação de uma sistemática de cobrança de proteção e preservação da memória ferroviária ao Estado, disputando lugar na cena dos monumentos históricos, artísticos e culturais valorados como bens nacionais. $O$ alcance do reconhecimento público e social desses bens é assunto de interesse recente pela academia, no entanto, se tornou um segmento importante de investigação. Este trabalho auxilia no avanço da compreensão sobre o tema e também em relação ao período significativo na consolidação da democracia na sociedade brasileira. Utilizou como fonte documentos oficiais do Preserve e amplo levantamento sobre as APFs, apresentando aqui recorte sobre a Associação Brasileira de Preservação Ferroviária (ABPF), no cenário dos novos movimentos sociais que surgiram no período.

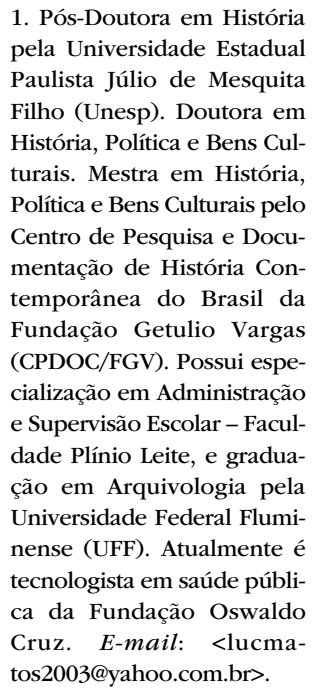
pela Universidade Estadual Paulista Júlio de Mesquita (Unesp). Doutora em turais. Mestra em História Política e Bens Culturais pelo Fundação Getulio Vargas (CPDOC/FGV). Possui especialização em Administração dade Plínio Leite, e graduação em Arquivologia pela Universidade Federal Fluminense (UFF). Atualmente é ologista em saúde públitos2003@yahoo.com.br>. 
PALAVRAS-CHAVE: Patrimônio ferroviário. Democracia. Associação de Preservação Ferroviária. Preserve.

ABSTRACT: This article contains reflections on the process of valuing and recognizing the cultural heritage of railways, which emerged throughout the 1980s, interpreting it as an important element in structuring the right to culture, identity and national heritage. The text presented is based on research on the railway past and its displacement from the object of actions restricted to festive celebrations for its takeover as public policy. It briefly presents the analysis of the Historical Heritage Preservation Program (Preserve) and the railway preservation associations (APFs). Two contemporary initiatives that helped to consolidate a system for charging protection and preservation of railway memory to the State, competing for a place in the scene of historical, artistic and cultural monuments valued as national goods. The reach of public and social recognition of these goods is a matter of recent interest by the academy, however, it has become an important segment of investigation. This work helps to advance the understanding of the theme and also in relation to the significant period in the consolidation of democracy in Brazilian society. It used official documents from the Preserve as source and extensive survey on the APFs, presenting here an excerpt about the Brazilian Association of Railway Preservation (ABPF), in the scenario of the new social movements that emerged in the period.

KEYWORDS: Rail heritage Democracy. Railway Preservation Association. Preserve. 
2. Cf. Schoppa (2008); Rodriguez (2004).

Este trabalho se propõe a debater o processo de valorização da preservação do patrimônio ferroviário brasileiro sob a leitura de um conjunto de fatores ocorridos na década de 1980, considerando o surgimento de movimentos sociais, que incentivaram e contribuíram para a construção do direito à cidadania, à cultura e endossaram desejos democráticos que se consolidaram na Constituição brasileira de 1988 e ainda repercutem na atualidade. $\bigcirc$ movimento de requisição do direito à memória, à identidade e ao passado ferroviário como um atributo devido pelo Estado brasileiro teve longa caminhada e, neste texto, pretendemos apresentar de forma sucinta algumas indicações dessa trajetória de modo a introduzir o debate ainda cadente, mas profícuo, que deve ser aprofundado, qual seja, a interpretação desse período como um marco na história da ferrovia e do patrimônio cultural brasileiro que colaborou para o processo democrático em curso.

A ferrovia brasileira tem sua origem mais concreta na Estrada de Ferro Mauá, criada pelo conhecido Barão de Mauá e inaugurada em 30 de abril de 1854, no estado do Rio de Janeiro, cujo propósito era transportar a produção de café do Vale do Paraíba. Desde esse período, a malha nacional cresceu exponencialmente. Logo em 1858 foi inaugurada a Estrada de Ferro Recife-São Francisco, no estado de Pernambuco, e a Companhia Estrada de Ferro D. Pedro II (posterior E.F. Central do Brasil). Ao fim do Império (1889), existiam 66 novas vias férreas que atendiam às regiões Norte, Nordeste, Sul e Sudeste, somando 9.587,2 quilômetros de linhas. Desse conjunto, 22 eram administradas pelo governo. ${ }^{2}$ Ao longo das primeiras décadas da República, o sistema ferroviário oscilou entre momentos de grande expansão e outros de contingenciamento. $\mathrm{Na}$ década de 1950, importante período na história ferroviária, o quadro se apresentava decadente, com material rodante precário e insuficiente. ${ }^{3}$ Os problemas se apresentavam nas esferas da gestão, das operações, mas, sobretudo, no quesito recursos humanos. Dentro dessa conjuntura, o Banco Nacional de Desenvolvimento Econômico (BNDE) - atual BNDES - propôs, em 1955, um conjunto de medidas que resultaram na criação da Rede Ferroviária Federal S.A., em 1957, empresa de economia mista formada pela incorporação de 22 estradas de ferro. ${ }^{4}$

À época, a malha nacional era composta também por outras linhas, como a E.F. Sorocabana, a E.F. Paulista, a E.F. Mogiana, a E.F. Araraquara e a E.F. São Paulo-Minas, administradas pelo estado de São Paulo ou em regime de concessão estadual. Em 1971, essas vias formaram o sistema da Ferrovia Paulista S.A. (Fepasa), que foi incorporado, em 1998, à RFFSA, em pleno processo de desestatização. guez (2004); Jacob (1982).

4. As estradas que formaram a Rede foram a Rede Mineira de Viação (RMV), a Viação Férrea do Rio Grande do Sul (VFRG), a E.F. Central do Brasil, a E.F. Leopoldina, a Rede de Viação Paraná-Santa Catarina (RVPSC), a Rede Ferroviária do Nordeste (RFN), a Viação Férrea Federal Leste Brasileiro (VFFLB), a E.F. Nordeste do Brasil (EFNOB), a Rede de Viação Cearense (RVC), a E.F. Bahia a Minas, a E.F. São Luís a Teresina, a E.F. Goiás, a E.F. Madeira-Mamoré, a E.F. Nazaré, a E.F. Bragança, a E.F. Dona Tereza Cristina, a E.F. Mossoró a Souza, a E.F. Central do Piauí, a E.F. Santa Catarina, a E.F. Santos a Jundiaí e a E.F. Ilhéus.
3. Cf. Schoppa (2008); RodriSampaio Correa, a E.F. 
5. Cf. Paula (2000).

6. Cf. Jacob (1982).

7. Cf. Schoppa (1985); Rodriguez (2004).

8. Cf. Schoppa (1985).

9. Cf. Schoopa (2008).

10. Em 1990 o Brasil reeditou o PND, iniciado em 1981, que tinha como um dos seus objetivos a reordenação da "[...] posição estratégica do Estado na economia, transferindo à iniciativa privada atividades indevidamente exploradas pelo setor público" (BRASIL, Lei ${ }^{\circ} 8.031,1990$, art. $1^{\circ}$, alínea I). Em decorrência do Programa, desde 1981, um conjunto de empresas foi transferido para a iniciativa privada, em um processo que ficou denominado reprivatização. Maiores detalhes sobre esse assunto podem ser obtidos na leitura da dissertação de Paradela (1998) e também em Inez Stampa. Nos trilhos da privatização. São Paulo: Annablume, 2011.
Em 1960, foi implantado um programa de erradicação de ramais antieconômicos, impulsionado, no ano seguinte, pela criação da Comissão para Extinção dos Ramais Antieconômicos. Dilma Andrade de Paulai ${ }^{5}$ explica que, naquele ano, foi criado um grupo de trabalho com o objetivo de identificar as estradas de ferro ou ramais deficitários. A supressão de ramais antieconômicos era vista como pré-condição para a recuperação do sistema ferroviário. Para Jacob, ${ }^{6}$ a decisão de erradicar ramais não contou com estudos prévios para proposição de outras medidas de contenção e isso teria promovido uma espécie de euforia na extinção de linhas. Ao fim desse período, a RFFSA reestruturou seu modelo de gestão, implantando um sistema regionalizado com divisões sediadas em quatro capitais. Em 1976, nova estrutura foi implantada, originando seis superintendências regionais e uma divisão: Recife (SR 1); Belo Horizonte (SR2); Rio de Janeiro (SR3); São Paulo (SR4); Curitiba (SR5); Porto Alegre (SR6); Divisão Operacional de Tubarão (SC). Em 1979 foi criada a SR7 em Salvador, pelo desmembramento da SR1 Recife, atendendo à região de Bahia e Sergipe. A sede da SR3 foi transferida para Juiz de Fora e foi criada a Divisão Operacional de Campos. ${ }^{7}$

Na década de 1980, o sistema ferroviário era composto pela E.F. Amapá (EFA), de 1957; E.F. Vitória Minas (EFVM), de 1903; RFFSA, de 1957; Ferrovia Paulista S.A, de 1971; E.F. Campos do Jordão (EFCJ), de 1914, de caráter turístico. Além daquelas particulares E.F. Jari, E.F. Votorantim e E.F. Perus-Pirapora. A RFFSA possuía então 12 escritórios regionais (Recife, Salvador, Fortaleza, São Luís, Belo Horizonte, Juiz de Fora, São Paulo, Bauru, Curitiba, Porto Alegre, Campos e Tubarãol e um escritório central, no Rio de Janeiro, estrutura que vigorou até a sua extinção, em 2007.8

Entre percalços, estratégias de gestão e de planejamento e programas de recuperação, interpretados por autores como Schoopa ${ }^{9}$ como medidas equivocadas ou insuficientes, a RFFSA foi considerada deficitária, dentro do projeto neoliberal de gestão, implantado à época, e assim incluída no Programa Nacional de Desestatização (PND), em 1992. 10 Desse ponto em diante a configuração da malha brasileira foi alterada, atendendo ao modelo de concessão, e a empresa entrou em processo de extinção moroso e prejudicial aos bens históricos, artísticos e culturais.

É dentro desse contexto que começou a surgir os primeiros movimentos de valorização do passado ferroviário, nos idos dos anos de 1980. Um panorama complexo, resumido aqui apenas como introdutório e base ao debate, mas privilegiado e propício para o processo de reivindicações que se estabelecera.

O texto apresentado está estruturado em duas seções. Na primeira parte, abordamos a implantação do Programa de Preservação do Patrimônio Histórico (Preserve), de modo a destacar como o patrimônio passou a ganhar destaque, a 
ponto de se tornar uma política pública. Na segunda parte, tratamos das associações de preservação ferroviárias (APFs), que serviram de base à leitura do patrimônio ferroviário como uma categoria requerida sob a lógica do direito social e cultural que se conformava naquele período, no quadro dos novos movimentos sociais que reivindicavam memórias e identidades culturais.

\section{O PROJETO PÚBLICO DE PRESERVAÇÃO DO PATRIMÔNIO FERROVIÁRIO}

A Rede Ferroviária Federal S.A., ao longo da década de 1970, como demostram as matérias da Revista Ferroviária e da Revista Ferrovia, " trabalhava com ações voltadas para a criação do museu ferroviário de Recife e na operação do trecho de São João del-Rei, que continha elementos históricos, além de exposições itinerantes realizadas por algumas superintendências regionais. A esse tempo, o patrimônio ferroviário, no que se refere ao campo do patrimônio industrial ou da arqueologia industrial e sobre políticas de proteção ao patrimônio público, era objeto de atenção recente. $\bigcirc$ primeiro museu ferroviário brasileiro surgiu por iniciativa da Fepasa, em 1972.

Em 1980, foi criado pelo Ministério dos Transportes o Programa de Preservação do Patrimônio Histórico (Preserve), ${ }^{12}$ voltado para todos os segmentos do setor dos transportes. Era operado por uma secretaria-geral, coordenada ininterruptamente (de 1980 a 1989) pela museóloga Maria Elisa Carrazzoni, que, entre 4 de novembro de 1970 e 16 de dezembro de 1976, dirigiu o Museu Nacional de Belas Artes. O Ministério tinha a atribuição de elaborar as diretrizes, acompanhar e apoiar o trabalho, enquanto os órgãos vinculados desempenhavam atividades alinhadas às diretrizes do programa por meio de grupos de trabalho constituídos nos órgãos. ${ }^{13}$ Teve como motivação "[...] denúncias de deterioração de documentos, prédios e peças que representam a história dos transportes no Brasil, com a agravante de parte desse material ser destinado à sucata sem nenhum estudo prévio". ${ }^{14}$ Funcionou durante dez anos e fundou centros, núcleos e museus.

Com a criação do Preserve, a RFFSA ampliou sua atuação e integrou o grupo de trabalho, alocado na sua sede, na cidade do Rio de Janeiro, e implantou espaços voltados para a divulgação e preservação dos acervos históricos, artísticos e culturais, conforme preconizava as diretrizes do Preserve. Também produziu documentos técnicos e informacionais como a "Norma para Execução do Inventário de Edificações de Interesse Histórico da RFFSA", de 1985, e o "Manual de Preservação de
11. Sobre as matérias publicadas nas revistas, cf. Matos $(2015 ; 2010)$.

12. Integraram o Programa o Departamento Nacional de Estradas de Rodagem (DNER), a Companhia Brasileira de Trens Urbanos (CBTU), a Empresa Brasileira de Transporte Urbano (EBTU), a Empresa Brasileira de Planejamento de Transportes (Geipot), a Empresa de Portos do Brasil S.A. (Portobrás), Cia. Docas da Bahia (Codeba), Cia. Docas do Espírito Santo (Codesa), Administração do Porto de Recife, Administração do Porto de Manaus, Cia. Docas do Rio de Janeiro (CDRJ), Cia. Docas do Pará (CDP), Companhia Docas de Imbituba, Superintendência Nacional da Marinha Mercante (Sunamam), 189 Companhia de Navegação do São Francisco (Franave), Companhia de Navegação Lloyd Brasileiro (Lloydbrasa), Marinha do Brasil, a Aeronáutica, a Empresa de Engenharia Ferroviária S.A. (Engefer), subsidiária da Rede, e a Rede Ferroviária Federal S.A.

13. Cf. Brasil (1980).

14. Brasil (1989, [s. p.]). 
15. Sobre o Preserve e o Preserfe, cf. Matos (2019; 2015).

16. Associação de Engenheiros Ferroviários (2008).

17. A Carta é resultante do II Congresso Internacional de Arquitetos e Técnicos dos Monumentos Históricos e representa uma síntese da Teoria do Restauro de Cesare Brandi. (Icomos - Conselho Internacional de Monumentos e Sítios Históricos/Unesco).

18. Sampaio (1987, p. 2).

19. Cf. Brasil (1982a, 1989).

20. Cf. Brasil (1981a).
Edificações Ferroviárias Antigas", de 1991, e o informativo Passado e Presente. Além de intervenções importantes, como a reforma da Rotunda de São João del-Rei.

Em 1985, reconfigurou sua participação e criou o Setor de Preservação do Patrimônio Histórico Ferroviário (Preserfe), ${ }^{15}$ subordinado à Superintendência de Patrimônio. Posteriormente, foi transformado na Gerência de Preservação do Patrimônio Histórico Ferroviário, exercida pelo arquiteto Cláudio Terêncio Marques Bacalhau. ${ }^{16}$

As intervenções e concepções de preservação do patriônio vigente no Preserfe tem referências teóricas e práticas alinhadas às recomendações da Organização das Nações Unidas para a Educação, a Ciência e a Cultura (Unesco) bem como às cartas patrimoniais, como à Carta Patrimonial de Veneza, de 1964.17

Os documentos produzidos também apresentavam a categoria do patrimonio cultural, pelo que é citado por Antônio José Pedral Sampaio,

[...] compreende vários seguimentos de uma cultura: "A língua falada, a música produzida, os usos e costumes, os bens materiais e naturais, as técnicas, os acontecimentos, o 'Saber Fazer' objetos, artefatos ou as construções que são criadas, desenvolvidas e herdadas por um novo povo, nação ou comunidade". Enfim, todo o universo cultural de um grupo social. ${ }^{18}$

A RFFSA implantou sete Centros de Preservação da História Ferroviária (CPHF): São João del-Rei, MG; Recife, PE; Fortaleza, CE; Curitiba, PR; Rio de Janeiro, RJ; São Leopoldo, RS; Paranapiacaba, SP. E cinco Núcleos Históricos: Belo Horizonte, MG; Campos, RJ; Juiz de Fora, MG; Miguel Pereira, RJ; Bauru, SP. Havia a pretensão expressa de implantar um CPHF em cada regional da RFFSA, porém, pelo levantamento, ela não foi concretizada. ${ }^{19}$

Os centros tinham a configuração de complexos com multiespaços, dispondo bens móveis, materiais rodantes, documentos e demais objetos. Estavam implantados em edificações ferroviárias, cuja arquitetura também servia à contemplação. Poderiam ser compostos por núcleos museológicos, bibliotecas, fototecas e arquivos históricos, no mínimo. Alguns possuíam espaços para lazer, restaurantes, áreas externas jardins e lojas de suvenires. Poderiam compor narrativas históricas apresentando a origem do transporte ferroviário de forma universal ou restringindo ao universo nacional, porém era recomendado retratar a história ferroviária local. ${ }^{20}$

Cumpriam o objetivo de disseminar a história dos transportes, mas também assumiam a função de edificar uma cultura da preservação ferroviária, elegendo referenciais valorados na composição de uma memória oficializada por meio de um complexo trabalho de eleição de objetos, personagens, datas, monumentos, paisagens culturais e, também, pela apropriação do território. Com base na leitura do artigo de 
Michael Pollak, entende-se que atitudes como essa possuem estreita referência "[...] na tradição metodológica durkheimiana, que consiste em tratar fatos sociais como coisas $[\ldots]^{\prime \prime}$. O autor também explica que o esforço em materializar serve para

[...] tomar esses diferentes pontos de referência como indicadores empíricos da memória coletiva de um determinado grupo, uma memória estruturada com suas hierarquias e classificações, uma memória também que, ao definir o que é comum a um grupo e o que, o diferencia dos outros, fundamenta e reforça os sentimentos de pertencimento e as fronteiras socioculturais. ${ }^{21}$

O primeiro centro foi instalado em São João del-Rei, em 29 de agosto de 1981, em comemoração ao centenário da E.F. Oeste de Minas (Efom). Ocasião em que foi publicado o documento "Museu Ferroviário de São João del-Rei - $1^{\circ}$ Centenário da Estrada de Ferro Oeste de Minas, 1881 - 1981".22 Em 1982, foram inaugurados os de Pernambuco, Ceará e Paraná. $\bigcirc$ primeiro resultou da remodelagem do Museu do Trem de Recife, existente desde 1972 e continha bens históricos da Companhia Great Western of Brasil Railway. O segundo foi montado no bairro operário de Fortaleza e inaugurado em 10 de setembro. $\bigcirc$ antigo prédio da administração das Oficinas de Demósthenes Rockerte, originário da Rede de Viação Cearense, serviu de instalação. A implantação contou com o apoio da Secretaria Estadual de Cultura e era constituído de um núcleo museológico que exibia a réplica da Estação de Riachão. O acervo continha a locomotiva batizada de "Fortaleza", a primeira a trafegar no Estado, e a locomotiva "Marta Rocha", utilizada no período da II Guerra Mundial. O superintendente de Produção da Regional de Fortaleza, engenheiro civil Francisco Roberto de Sant'Ana, na apresentação do espaço, dá a dimensão dos significados atribuídos a esses lugares: "[...] um verdadeiro TEMPLO, destinado a abrigar a história, cultura e tradições ferroviárias da nossa terra". E complementa que servirá para "[...] irradiar e divulgar, cada vez mais, o esforço, idealismo e capacidade operosa dos ferroviários cearenses: artífices, mestres, engenheiros e, enfim, de todos que pelejaram em prol da causa ferroviária, do litoral aos sertões nordestinos". ${ }^{23}$

O CPHF do Paraná é de 15 de dezembro e ocupava a antiga Estação Central Ferroviária de Curitiba. Fazia referências à história da Rede de Viação Paraná-Santa Catarina, com ênfase ao trecho Paranaguá-Curitiba, no qual existia uma linha turística. Dava destaque aos engenheiros João Teixeira Soares e Antônio Pereira Rebouças, construtores ferroviários que trabalharam no referido trecho referenciado como detentor de "[...] obras consideradas, hoje, das mais difíceis na engenharia nacional" ${ }^{24} \bigcirc$ centro também firmou parceria com o Serviço Nacional de Aprendizagem Industrial (Senai) para o desenvolvimento de atividades educativas.
21. Pollak (1989, p. 3).

22. Cf. Brasil (1981b).

23. Brasil (1982a, [s. p.])

24. Brasil (1982b, p. 17; 1989, p. 22) 
25. Brasil (1984, [s.p.]).

26. Brasil (1985b, p. 9).

27. Brasil (1985a, p. 8).
Em 25 de fevereiro de 1984 foi inaugurado o CPHF do Rio de Janeiro, nos gal pões das Oficinas do Engenho de Dentro, oriundas da E.F. Central do Brasil. O local pertencia às primeiras oficinas ferroviárias destinadas à manutenção de materiais rodantes, de onde se originou o bairro. Continha a locomotiva "Baroneza", o carro do Imperador, o carro usado pelo rei Alberto da Bélgica quando esteve em visita ao país, em 1920, e o carro do presidente Getulio Vargas, utilizado na década de 1930. Sobre essas peças, Maria Elisa Carrazzoni, diz que "os carros nobres, assim chamados por terem sido construídos para servir a altos dignitários tais como reis, papas e governantes, são, sem dúvida, o ponto alto do acervo reunido no Engenho de Dentro" ${ }^{25}$ Os materiais faziam referencia à E.F. Mauá, à E.F.D. Pedro II, à E.F. Central do Brasil e à E.F. Leopoldina, além das figuras de D. Pedro Il, do Barão de Mauá, dos engenheiros Cristiano Benedicto Ottoni, Francisco Pereira Passos e André Gustaro Paulo de Frontin e do empresário e políitico Mariano Procópio.

O CPHF do Rio Grande do Sul foi inaugurado em 9 de março de 1985, na antiga estação da cidade de São Leopoldo, indicada como a primeira do estado. Assim como nos demais, apresenta suas características e materiais ferroviários como singulares, únicos e originais. ${ }^{26}$ Ainda em 1985, foi fundado o centro de São Paulo, instalado na Vila de Paranapiacaba, em Santo André, SP. A ausência de preservação do local motivou a instalação do centro que serviu de disputa entre a ABPF, o Preserfe e resultou no Movimento Pró-Paranapiacaba.

De modo geral, os centros desenvolviam atividades de cunho educativo e socioculturais, com visitas guiadas, festas comemorativas - dia das mães (RJ) - , concurso "Jovem Pesquisador" (CE) de 1984, nas quais o pesquisador deveria ter utilizado documentos do acervo, gincanas, teatro de fantoches, visitas escolares e passeios de trem. Maria Elisa Carrazzoni explica que o objetivo do programa não estava restrito aos bens materiais, mas

[...] acima de tudo à valorização do homem, daquele que, vencendo obstáculos de toda ordem e em todos os níveis, soube adaptar a tecnologia dos transportes, vinda de países em estágio de desenvolvimento mais adiantado, as nossas necessidades. Desde o engenheiro ao mais simples trabalhador de linha, ao marinheiro, ao operário das oficinas de manutenção, o nosso trabalho procura mostrar os traços da inteligência, do preparo técnico e da dedicação que deixaram na sua vida profissional. ${ }^{27}$

Observamos que, substancialmente, os homens valorizados nos espaços ferroviários referiam-se aos pioneiros que sumariamente estavam representados na figura dos engenheiros, com exceções aos centros do Paraná e do Rio Grande do Sul, que incluíram o "homem comum". 
A implantação do Preserfe ajuda a entender o papel da Rede Ferroviária na valorização do passado e, como aqui defendemos, no contexto da emersão dos novos patrimônios nacionais que passaram a configurar no quadro de busca pelo reconhecimento público como direito social, à cultura e ao patrimônio. Nascia, à época, uma noção coletiva em relação ao passado ferroviário, inclusive com o acionamento do Iphan para a proteção dos bens ferroviários. No entanto, como contraponto, Welber dos Santos entende que
A patrimonialização, ou a museificação, da ferrovia na década de 1980 parece ter um sentido ambíguo, ou ambivalente. Ao contrário do discurso encontrado na documentação oficial sobre a criação dos centros, de que seriam instituições de reconhecimento da importância desses meios de transporte historicamente, me parece mais um esforço institucional do estado autoritário para se fazer parecer reconhecedor do legado por ele mesmo sucateado e, por outro lado, uma pequena vitória da sociedade civil inconformada com a dilapidação dos bens e as erradicações dos ramais ferroviários desde a década de 1960.28

Na década de 1990, a Rede passou a fundar os Centros Ferroviários de Cultura (Cefecs), em regime de parceria com prefeituras por meio do Programa Ferroviário de Ação Cultural (Profac), uma espécie de continuidade do Preserfe que se propagou até o ano de 1996. As atividades foram gradualmente abandonadas e, segundo Welber Santos e Rubem Ladeira, ${ }^{29}$ o fato deu-se em grande parte por conta da desestatização da Rede Ferroviária, iniciado em 1992.

Porém, com o início do processo de desestatização da RFFSA no ano de 1995, diversos técnicos do PRESERFE aderiram ao Programa de Demissão Voluntária e, sem pessoal, o Museu entrou em declínio. Ainda houve uma tentativa de alavancar o programa de preservação da memória ferroviária, quando foi incluído no pacote financeiro do Banco Mundial, que tratava deste processo de desestatização, uma dotação orçamentária para recuperação dos museus existentes. Por ordem do então presidente da RFFSA, Sr. Isaac Popoutchi, foram desenvolvidos dois projetos para aplicação inicial destes recursos: ampliação do Museu do Rio de Janeiro e a recuperação do Museu de São João del-Rei. Todavia, com a mudança de direção da Empresa, estes projetos foram arquivados e os recursos abandonados. ${ }^{30}$

Após a dissolução, os espaços foram, em grande medida, assumidos pelas concessionárias e por municípios, não de forma automática, mas a partir de mobilizações populares. Outros foram apoiados pelas associações preservacionistas, que assumiram a defesa dos remanescentes do projeto preservacionista. Alguns integrantes da Rede passaram a compor entidades preservacionistas, como Rubem Ladeira, Victor José Ferreira, João Bosco Setti e Maria Inês Mazzoco, por exemplo. 
31. Cf. Brasil (2007).

32. Cf. Reis (2013).

33. Cf. Fonseca (1996).
A iniciativa preservacionista do Estado e da Rede atendeu, em boa medida, às demandas sociais pela proteção dos bens ferroviários. Porém, não abarcou totalmente o universo patrimonial fragilizado e exposto à degradação. Acrescido ao processo de extinção iniciado na década seguinte, o fator acabou por estimular a continuidade das pressões, a fundação de associações - que saiu de uma em 1977 para 23 em 2000 -, e o acionamento do Iphan pelo crescimento de pedidos de tombamento. Ademais, entendemos que o modelo formatado pelo Preserfe foi parcialmente absorvido pelo Iphan quando foi preciso atender aos pressupostos da Lei $n^{\circ} 11.483 / 07,{ }^{31}$ que transferiu ao órgão a responsabilidade pela preservação do acervo da ferrovia brasileira. Portanto, os programas teriam colaborado tanto na edificação do passado da ferrovia quanto no processo de patrimonialização da memória ferroviária na atualidade. Como exemplo, podemos citar a aplicação de inventários para mapear o conjunto do acervo ferroviário espalhado pelo país, que se estende para além de locomotivas, estações e vagões. Também foram estabelecidas parcerias com entidades regionais/locais, com outros entes públicos, como prefeituras, e privados no intuito de partilhar a manutenção de espaços ferroviários. Além do estabelecimento de mecanismo para o envolvimento da sociedade geral na busca de soluções de preservação dos bens, como a realização de fóruns e eventos. Outro indicativo de aproximação com as ações realizadas pelo Preserve foi a criação de unidades de preservação, similares aos centros e museus. As associações preservacionistas tiveram papel importante nesse movimento junto ao Iphan.

\section{O SURGIMENTO DAS APFS NA DEFESA DO DIREITO AO PATRIMÔNIO E À MEMÓRIA FERROVIÁRIA}

De forma incipiente, indivíduos começaram a se reunir em torno do patrimônio ferroviário ainda na década de 1970 e passaram a formar associações, classificadas atualmente como organizações civis não governamentais, seguindo definição estabelecida por Reis. ${ }^{32}$ Entendemos que a atuação desses grupos e suas demandas estão alinhadas à matéria do direito à cultura, ao patrimônio e à cidadania, áreas que sofreram significativas modificações no cenário nacional e internacional, sobretudo na década de 1980. Segundo Maria Cecília Londres Fonseca, ${ }^{33}$ ocorreu um realinhamento no sentido e no uso políitico do patrimônio. Se no projeto construído nos primórdios da formação do Iphan, em 1937, o objetivo era a formação de uma identidade nacional, nos fins da década de 1970, a diversidade cultural brasileira passou a ser considerada na políitica e nas práticas de preservação do patrimônio nacional que, no decurso dos 
anos 1980, alinharam-se à ideia do direito cultural. É nesse contexto que foi possível a entrada e a profusão das associações de preservação no seio das práticas preservacionistas desenvolvidas pelo poder público e valorizadas pela sociedade. $\bigcirc$ patrimônio industrial, que inclui os meios de transportes, passou a receber a atenção de preservacionistas britânicos desde a década de 1950, em função da perda de dois grandes monumentos: a Euston Station e o Coal Exchange, referências da época industrial. Após esses episódios, o acervo ferroviário passou a ser objeto de igual atenção, com o objetivo de preservar o material considerado obsoleto (ou arcaico). ${ }^{34}$

A primeira associação de presenação ferroviária (AFP) ${ }^{35}$ foi fundada em 1977, com o ideal de recuperar, restaurar e operar peças e materiais abandonados e degradados pelo tempo e pelo "descaso" das autoridades públicas, com risco de se perderem do traço da história ferroviária. A Associação Brasileira de Preservação Ferroviária (ABPF), formada pela iniciativa do francês Patrick Henri Ferdinad Dollinger, associado a Sérgio José Romano e Juarez Spaletta, pretendia inicialmente tornar a prática do colecionismo e da montagem de trens grandes uma experiência presente na realidade brasileira, similar aos costumes correntes na Europa e nos Estados Unidos.

grupo indica a administração de museus e operações de trens turísticos como ações que garantiriam a preservação dos materiais ferroviários. Observamos que o modelo adotado pela ABPF, que escolhe trechos desativados para implantar passeios de fim de semana, supervalorizando a operação e o maquinário, é compatível com o desenvolvido pelos norte-americanos, como exemplo, o existente no trecho da antiga Denver \& Rio Grande Western Railroad, entre os estados de Colorado e Novo México. O passeio conta com locomotivas, carros e "Gondola Car" - um tipo de carro aberto, para trens especiais ou turísticos. ${ }^{36}$

A ABPF, orientada pelos ideários dos três voluntários, logo começou a operar com estrutura robusta. $\bigcirc$ grupo foi formalizado como pessoa jurídica sem fins lucrativos, regulamentado por estatuto social, com caráter instrutivo, cultural e recreativo. Tornou-se ao longo da história uma interlocutora importante com o poder público e uma fiscalizadora assídua das condições de conservação dos objetos ferroviários, participando ativamente da cena preservacionista e remodelando a conjuntura da década de 1970-1980. O seu modelo senviu de base para a fundação de outras associações. De imediato, a ABPF conseguiu, em comodato com a RFFSA, a cessão de 13 locomotivas a vapor. Em 1979 iniciou a operação de viagens em locomotivas a vapor, que percorriam o trecho de 24,5 quilômetros entre a Estação de Anhumas/Campinas e a cidade de Jaguariúna, recebido em comodato da Fepasa. Em 1984, o trecho tornou-se um complexo, formado por um museu e pela operação do trem, intitulado de Museu Dinâmico Viação Férrea Campinas-Jaguariúna. Esse seria o primeiro empreendimento gerido por uma associação preservacionista.
34. Pilcher (1997, p.132-140).

35. Sobre as APFs, cf. Matos (2010).

36. American Heritage Railways $(s . d$.). 
Algumas atuações são apontadas como emblemáticas pelo grupo, como a interferência no caso de São João del-Rei, onde executou uma campanha pleiteando a preservação da estrada, o que teria incentivado o trabalho do Preserfe; e as solicitações de tombamento, como a do trecho entre Aureliano Mourão, São João del-Rei e Antônio Carlos, no município mineiro de Ribeirão Vermelho, e a da E.F. Perus-Pirapora, em São Paulo, ambas em 1983. Nesse último caso, o grupo reivindica a participação na elaboração do projeto junto ao Condephaat para a transformação do trecho em ferrovia histórica e turística. Também é citada a restauração da locomotiva n 353, da E.F. Central do Brasil, que passou a ser símbolo da RFFSA. Além disso, o grupo divulga ações de apoio a mobilizações realizadas por movimentos sociais, como o da E.F. Madeira-Mamoré, que foi tombada pelo Iphan em 1987, e a operação, entre 1986 a 1992, do "único sistema funicular ferroviário do mundo com lobobreques", na Vila de Paranapiacaba, entre o quinto e o quarto patamares da São Paulo Railway na Serra do Mar, em Paranapiacaba.

No decurso dos anos, a ABPF aprimorou a relação com os representantes do poder público, como a RFFSA, a Fepasa, o lphan, o Condephaat e algumas prefeituras. $\bigcirc$ grupo também concorre para tornar-se consultor em planos de recuperação de bens históricos em parceria com municípios e demais associações, como no caso da Associação Nacional de Preservação Ferroviária (ANPF). Atualmente, tem filiais em quatro estados da federação: São Paulo, Rio de Janeiro, Santa Catarina e Minas Gerais, expansão iniciada em 1989 com a fundação da Regional-Rio. A associação tornou-se a maior representante do ramo, tanto no sentido do prestígio quanto pelo patrimônio acumulado ao longo de mais de três décadas de operação. Ela é detentora de um conjunto volumoso e valoroso de peças, materiais rodantes e instalações adquiridas, comumente, por meio de comodatos.

Por aproximados oito anos, a ABPF era a única representante da categoria de associações preservacionistas. Na década de 1980, surgiram dois grupos, e, nos anos 1990, iniciou-se um amplo movimento de edificações de entidades, formando a cartografia atual. Em 8 de abril de 1984, foi criada a Associação de Preservação da Memória Ferroviária (APMF) na cidade de São Paulo. De caráter cultural, tinha o objetivo de preservar a memória e as tradições ferroviárias. Foi idealizada e ainda é liderada pelo advogado e engenheiro Sérgio Feijão Filho, que integrou anteriormente a ABPF. Em 1982, Feiijão Filho encaminhou carta ao Iphan solicitando dados sobre a E.F. Madeira-Mamoré, em processo de tombamento, buscando aproximar-se dos executores do projeto de revitalização. Em 1989, Feijão Filho encaminhou carta à Revista Ferroviária, solicitando ajuda de especialistas na recuperação da locomotiva $n^{\circ} 611$, adquirida pelo grupo. Essa associação é 
reconhecida oficialmente como uma entidade nacional, mas observa-se sua atuação de forma restrita ao território paulista. A partir de 2000, a APMF modificou sua designação e incluiu o caráter turístico e pedagógico entre suas finalidades e tem estabelecido convênios e apoiado outras associações, como foi o caso do município de Americana, em 2002, para recuperação da estação ferroviária local e restauração de bens móveis, imóveis e documentos da Companhia Paulista de Estrada de Ferro, e da fundação da Associação Mogiana de Preservação Ferroviária, em 2008, com quem tem desenvolvido projetos em parceria, como o "Trem da Cana", a ser implantado no município de Sertãozinho. ${ }^{37}$ Em 2013, a municipalidade de Tupã/ SP também solicitou ajuda para recuperar a região da Alta Paulista. ${ }^{38}$

Em 23 de julho de 1986 foi fundada a Sociedade Nacional Movimento Trem de Ferro ou, simplesmente, Movimento Trem de Ferro. Com sede em Salvador, a entidade permaneceu alguns anos sem atividades. Verificamos que seu desempenho começou a se estruturar de forma mais eficaz na década de 1990, quando assumiu parceria com o Grupo de Música Amazonas e Edições Tatau e o Grupo Ecológico Germen. Dessa união nasceu, em 1991, o projeto "Ver de Trem", que, no primeiro momento, tinha o objetivo de realizar uma espécie de "viagem-protesto", saindo de Salvador com destino ao Rio de Janeiro para participação na ECO 92 (Conferência das Nações Unidas sobre Meio Ambiente e Desenvolvimento, realizada em junho de 1992). O objetivo era chamar a atenção para a situação de negligência em relação ao transporte de passageiro, cujo foco era a revitalização da ferrovia. Em 1995, assumiu personalidade jurídica e vem se dedicando à implantação de um percurso turístico entre Salvador e Alagoinhas, além de continuar o projeto "Ver de Trem" ${ }^{39}$

Observamos que o quadro existente entre 1970 e 1980 era dominado pela ABPF, situação modificada na década de 1990, tanto pela proliferação de entidades, como pelo crescimento de projetos de trens turísticos. $\bigcirc$ número de associações mais que dobrou, surgindo sete novos grupos. Vale lembrar que em 1992 foi oficialmente anunciada a desestatização da RFFSA e, em 1998, a Fepasa foi incorporada ao espólio da Rede, resultando na sua extinção.

A década seguinte apresentou aumento significativo também. Novos 15 grupos foram identificados entre 2000 e 2015. A esse tempo, as concessões da malha ferroviária estavam consolidadas e a RFFSA estava em processo de esvaziamento, sendo declarada extinta em 2007, momento em que o Iphan foi declarado como responsável pela memória ferroviária, decisão recebida com agrado pelos grupos, pois encaixara-se às suas necessidades de dialogar com o poder público.

Há algumas indicações importantes a serem destacadas na formação das associações e na sua expansão. Observamos que uma rede de atores se formou,
37. Cf. Oliveira (2009).

38. Cf. Gil (2008).

39. Cf. Coelho (s. d.) 
40. Cf. Matos (2010).

41. Cf. Huyssen (2000); Hartog (2013); Meneses (1992). tendo como elo o trabalho na propria RFFSA. É o caso da formação da Associação de Engenheiros Ferroviários (Aenfer), criada em 1992, na cidade do Rio de Janeiro, a qual contava em seus quadros com ex-funcionários da RFFSA que tinham participado do Preserfe, como Rubem Eduardo Ladeira, esposo de Stella Ladeira, ex-integrante do Preserfe e ex-museóloga do Museu do Trem do Rio de Janeiro. Rubem também integrou a Associação Fluminense de Preservação Ferroviária (AFPF), a ABPF e o Movimento de Preservação Ferroviária (MPF). Recentemente, Rubem Ladeira participou como consultor da proposta de criação do Museu Ferroviário Nacional.

Outro ator importante, que auxilia ao exemplo destacado, é Victor José Ferreira. Ex-funcionário da RFFSA e integrante do Preserfe, fundou, com outros membros, o MPF em 1997, oficializado em 2003, na cidade do Rio de Janeiro. O grupo estimulou a fundação da Associação Brasileira das Operadoras de Trens Turísticos Culturais (Abottc) e fundou em 2008, em conjunto com outras entidades, - Grupo Fluminense de Preservação Ferroviária (GFPF) e, em 201 1, participou da criação da Academia Ferroviária de Letras, ambos idealizados por ele.

Há pontos no processo de formação das APFs que extrapolam o recorte temporal deste trabalho, mas merecem ser destacados. Ao longo dos anos, uma rede colaborativa e de interação, normalmente tendo a ABPF como núcleo, foi formada. Também percebemos que a operação de trens turísticos foi assumida como principal interesse e ferramenta de preservação nas práticas e narrativas das entidades. Com o advento da Lei n. 1 1.483, a Lei da Memória Ferroviária, em 2007, as entidades se adaptaram e remodelaram seus discursos e objetivos de modo a inserir o novo verbete e dimensões, incluindo-os nas suas reivindicações preservacionistas. A articulação entre os grupos e a pressão junto aos órgãos de proteção do patrimônio público, como os conselhos regionais e o Iphan, também são formas de atuação.

As APFs possuem uma composição muito diversificada, incluindo ferroviários e não ferroviários, estes citados por vezes como maioria. Todos eles estão envolvidos no ofício da preservação e promoção do trem como elemento histórico, contribuindo na afirmação da cultura da memória ferroviária. ${ }^{40}$ Autores como Huyssen, Hartog e Meneses, ${ }^{41}$ entre outros, ajudam a entender o movimento que ocorreu no universo das ferrovias, inserindo-o em um contexto mais amplo, de culto ao passado. Os grupos assumem um papel original e eminente ao reforçarem a consciência social sobre o passado das ferrovias e alargarem a presença do trem nas políticas de preservação em readequação. $\bigcirc$ caráter político e dinâmico assumido pelas associações, a apropriação de um passado em abandono e desuso, para forjar uma memória ferroviária idealizada, e a concorrência com as ações promovidas pelo Estado reforçam a interpretação dos grupos como agentes sociais que contribuíram na promoção - que se confunde 
com a própria construção - de uma memória ferroviária. Assim, teriam ocupado a lacuna deixada pelo Preserfe e se tornaram protetores e promotores das comemorações ferroviárias. Eduardo Oliveira, ${ }^{42}$ ao dedicar estudos sobre as comemorações, informa a necessidade de avançar sobre o assunto.

A leitura de José Reginaldo Gonçalves e Meneses ${ }^{43}$ permite interpretar que os preservacionistas ferroviários estabeleceram o patrimônio e a memória ferroviária como uma meta e a materializaram em um conjunto de objetos, forjando políticas que justificam a existência dos próprios grupos. Assim, recorrer ao discurso da perda, do abandono, do desaparecimento, da dilapidação tornou-se justificativa primordial do fazer preservador.

Há ainda muito a ser desvendado sobre o papel das associações ferroviárias. O recorte apresentado atende a este texto na medida em que auxilia a leitura sobre a emergência e a ressignificação do passado ferroviário mobilizado pelos grupos sociais.

\section{CONSIDERAÇÕES FINAIS}

Entendemos, com base nos estudos sobre a década de 1980, que o conjunto de medidas e pleitos que se estabeleceram no período pretendia colocar a cultura ferroviária em lugar de destaque, mas também teria contribuído para a valorização das novas categorias patrimoniais que emergiam no país. A estratégia recuperou personagens famosos na sociedade brasileira que depuseram em favor da preservação ferroviária. A escritora Rachel de Queiroz, em depoimento sobre - Centro de Preservação do Ceará, disse que era a oportunidade de recuperação de um "passado injustamente perdido". Para ela "parecia até que ninguém queria mais saber de trem. Pois era engano. Muita gente ainda os queria, aos trens". 44 Enquanto Gilberto Freyre, patrono do Museu de Recife, destacou a iniciativa como

Um passado sempre inspiração. Sempre didático. E não velharia desprezível. Daí haver em Sociologia, da melhor, uma expressão significativa: passado útil. Ou passado utilizável. Conceito também válido para uma Museologia, da melhor: a que faz dos museus, antes escolas vivas que simples depósitos de ossos. ${ }^{45}$

As breves notas reunidas neste artigo têm como objetivo principal chamar a atenção para dimensões para as quais ainda precisamos avançar e servem como estímulo a novas investigações. $\bigcirc$ campo da preservação do patrimônio cultural
42. Cf. Oliveira (2013).

43. Cf. Gonçalves (1996); Meneses (1992).

44. Brasil (1982a, [s. p.])

45. Brasil (1982c, p. 7) 
na década de 1980 ainda é recente e tem chamado a atenção de novos pesquisadores. Apresentar reflexões sobre a trajetória preservacionista da ferrovia serve como indutor e, por outro lado, tem a pretensão de alocar os esforços partilhados entre as instâncias públicas e as organizações civis dentro dos movimentos contemporâneos de valorização de identidades e culturas marginalizadas que passaram a acionar o Estado brasileiro para a formação de políticas públicas direcionadas. Nesse sentido, vale reforçar o papel das APFs como promotoras e interlocutoras que, a partir do surgimento da ABPF, ocuparam lugar importante e movimentaram o cenário. Não foi possível, para composição deste texto, medir a intervenção direta do Preserfe e das associações na elaboração das políticas públicas que se estruturam em períodos subsequentes. No entanto, há indícios importantes que dão conta da importância que esses movimentos ganharam. O Iphan recuperou práticas criadas pelo programa preservacionista e as associações, além de se multiplicarem, ganharam espaço público e político e passaram a participar de decisões em instâncias da RFFSA e mesmo dos órgãos de proteção, como o lphan. Há ainda muito a ser dito sobre esse momento histórico da ferrovia e suas contribuições à democracia e ao Estado brasileiro.

Um ponto importante a ser colocado tem relação com a conformação que as reivindicações à preservação do patrimônio ferroviário estabeleceram. $\bigcirc$ sistema ferroviário passava por remodelação e foi a demanda pública que atingiu a RFFSA e a participação das associações que auxiliaram no fomento da nova categoria patrimonial, a ferroviária. Ao mesmo tempo em que a empresa caminhava para sua desvalorização como bem público, os bens históricos, artísticos e culturais emergiam.

Embora não seja o propósito deste trabalho, é importante afirmar que as APFs continuam a atuar no campo da preservação ferroviária e, cada vez mais, assumem projetos preservacionistas, com destaque para as operações dos trens turísticos. Observamos que algumas práticas são similares àquelas desenvolvidas pelo Preserfe. Como exposto anteriormente, isso pode decorrer em função de parte dos integrantes terem trabalhado na RFFSA, mas também pela ABPF, que serve de exemplo a demais grupos, ter estabelecido parceria desde o princípio com a Rede e com outras instâncias públicas de proteção do patrimônio público. Além disso, - campo da preservação patrimonial cresceu substancialmente no país e o segmento ferroviário acompanhou essa trajetória.

É preciso ainda apontar a necessidade de ampliar os estudos em uma proposta comparativa com outros movimentos ocorridos na sociedade brasileira acerca da valorização de patrimônios específicos, de categorias, de segmentos sociais e/ou de empresas. Como exemplo, a Fundação Oswaldo Cruz criou em 1986 a Casa de Oswaldo Cruz com o objetivo de preservar a memória da instituição e contribuir para 
o conhecimento da história da saúde e das ciências biomédicas. Que outras instituições e organismos seguiram caminho semelhante? Como esses movimentos dialogam e/ou se aproximam do ocorrido na ferrovia? Reflexões para uma próxima investigação. 


\section{REFERÊNCIAS}

FONTES IMPRESSAS

BRASIL. Ministério dos Transportes. Portaria n. 292, de 24 de abril de 1980. Diário Oficial da União, Brasília, DF, 29 abr. 1980. Seção 2, p. 28.

BRASIL. Ministério dos Transportes. Diretriz para a instalação de centros de preservaçãoo da bistória ferroviária. Rio de Janeiro: Preserve/RFFSA, 1981a.

BRASIL. Ministério dos Transportes. Museu Ferroviário de São João Del Rei: $\mathbf{1}^{\circ}$ Centenário da Estrada de Ferro Oeste de Minas, 1881-1981. Rio de Janeiro, PREERVE/RFFSA/SR-2, 1981b.

BRASIL. Ministério dos Transportes. Catálogo Ceará. [S. l.: s. n.], 1982a.

BRASIL. Ministério dos Transportes. Catálogo Curitiba. [S. l.: s. n.], 1982b.

BRASIL. Ministério dos Transportes. Museu do trem. Recife, PRESERVE/RFFSA/SR-1, 1982c.

BRASIL. Ministério dos Transportes. Catálogo Rio. [S. 1.: s. n.], 1984.

BRASIL. Ministério dos Transportes. Relatório de atividades 1980-1984. Brasília, DF: Preserve/CCP, 1985a.

BRASIL. Ministério dos Transportes. Catálogo Rio Grande do Sul. [S. l.: s. n.], 1985b.

BRASIL. Rede Ferroviária Federal S.A. Relatório de Atividades 1980-1989. Brasília, PRESERVE/CCP, 1989.

BRASIL. Lei $\mathrm{n}^{\circ}$ 11.483, de 31 de maio 2007. Dispõe sobre a revitalização do setor ferroviário, altera dispositivos da Lei $\mathrm{n}^{\circ}$ 10.233, de 5 de junho de 2001 , e dá outras providências. Diário Oficial da República Federativa do Brasil, Brasília, DF, 31 de maio 2007. Disponível em: <https://bit.ly/3eSyboa>. Acesso em: 20 ago. 2019. 
ASSOCIAÇÃO DE ENGENHEIROS FERROVIÁRIOS. Trabalho apresentado no X seminário sobre preservação e revitalização ferroviária, realizado no dia 28 nov. 2008. Jornal Aenfer, ano XII, n. 126, nov./dez. p. 10, 2008.

COELHO, Franco. A viagem histórica da caravana Ver de Trem para a Eco 92. [on-line] [s. d.] Disponível em: <https://bit.ly/2Y8kQRQ>. Acesso em: 20 ago. 2019.

FONSECA, Maria Cecilia Londres. Da modernização à participação: a política federal de preservação nos anos 70 e 80. Revista do Patrimônio Histórico e Artístico Nacional. Iphan, n. 24, p. 153-163, 1996.

GIL, Izabel Castanha. Cooperação, competição e resistência nas associações de municípios: a AMNAP e o desenvolvimento regional da Nova Alta Paulista. Revista Nera, Presidente Prudente, ano 11, n. 12, jan./jun. 2008, p. 31-56.

GONCALVES, Jose Reginaldo S. A retórica da perda: os discursos do patrimônio cultural no Brasil. Rio de Janeiro: URFJ/Ministério da Cultura/Iphan, 1996.

HARTOG, Francois. Regimes de historicidade: presentismo e experiências do tempo. Belo Horizonte: Autêntica, 2013. (Coleção história e historiografia).

HUYSSEN, Andreas. Seduzidos pela memória: arquitetura, monumentos, mídia. Rio de Janeiro: Aeroplano, 2000.

JACOB, Chafic. Ferrovia, o caminho certo: panorama das estradas de ferro nos países de economia liberal e dirigida. São Paulo: Imprensa Oficial do Estado, 1982.

LADEIRA, Rubem. Entrevista. Rio de Janeiro. Associação de Engenheiros Ferroviários. Jornal Aenfer, ano XIII, n. 128, abr./maio, p. 4-5, 2009.

MATOS, Lucina Ferreira. Estação da Memória: um estudo das entidades de preservação ferroviária do Estado do Rio de Janeiro. 2010. Dissertação (Mestrado em História, Política e Bens Culturais) - Escola de Ciências Sociais, Fundação Getulio Vargas, Rio de Janeiro, 2010.

MATOS, Lucina Ferreira. Memória ferroviária: da mobilização popular à política pública de patrimônio. 2015. Tese (Doutorado em História, Política e Bens Culturais) - Escola de Ciências Sociais, Fundação Getulio Vargas, Rio de Janeiro, 2015. 
MATOS, Lucina Ferrreira. A entrada da Rede Ferroviária no campo da preservação do patrimônio público nacional. Revista CPC, v. 14, n. 27, p. 86-113, 2019.

MENESES, Ulpiano T. Bezerra de. A História, cativa da memória? Para um mapeamento da memória no campo das Ciências Sociais. Revista do Instituto de Estudos Brasileiros, São Paulo, n. 34, 1992.

OLIVEIRA, Eduardo Romero de. O centenário da ferrovia brasileira (1954): ensaio sobre a elaboração da memória ferroviária no Brasil. Espaço e Geografia, p. 675-717, 2013. Disponível em: <https://bit.ly/2MAzb4k>. Acesso em: 10 ago. 2019.

OLIVEIRA, Junia. Patrimônio: história volta aos trilhos. O Estado de Minas. 14 dez. 2009. Disponível em: <https://bit.ly/2UhdIBz>. Acesso em: 15 set. 2019.

PAUlA, Dilma Andrade de. Fim de Linha: A extinção de ramais da Estrada de Ferro Leopoldina (1955-1974). 2000.

PILCHER, Steve. Changing atitudes to the conservation of England's railway heritage. In: BURMAN, Peter; STRATTON, Michael. Conserving the Railway Heritage. London: E\&FN Spon, 1997, p. 133.

POLLAK, Michael. Memória, esquecimento, silêncio. Estudos Históricos, Rio de Janeiro, v. 2, n. 3, 1989, p. 3-15.

POLLAK, Michael. Memória e identidade social. Estudos Históricos, Rio de Janeiro, v. 5, n. 10, 1992, p. 200-212.

REIS, Elisa P. Introdução. In: REIS, Elisa P. (Org). In: ONGs: novos vínculos entre a sociedade e o Estado. Rio de Janeiro: 7 Letras, 2013, pp. 51-82.

RODRIGUEZ, Hélio Suêvo. A formação das estradas de ferro no Rio de Janeiro: Resgate de sua memória. Rio de Janeiro: Memória do trem, 2004.

SAMPAIO, Antônio José Pedral. Rede Ferroviária Federal S.A. Passado e Presente, n 1 dez., 1987.

SCHOPPA, Renê Fernandes. A ferrovia é viável. Rio de Janeiro: JMB Editores, 1985.

SCHOPPA, Renê Fernandes. 150 anos do trem no Brasil. Rio de Janeiro: Edição do autor, 2008. 
SITES

AMERICAN HERITAGE RAILWAYS. Train history. Durango. Disponível em: <http://www. durangotrain.com>. Acesso em: 20 ago. 2019.

SANTOS, Welber Luiz dos. Ordem e desordem contra bens culturais ferroviários. Blog Trilhos do Oeste. 2013. Disponível em: <https://bit.ly/2MzLzRX>. Acesso em: 15 set. 2019.

Artigo apresentado em 9/12/2019. Aprovado em 23/4/2020.

\section{(cc) BY}

All the contents of this journal, except where otherwise noted, is licensed under a Creative Commons Attribution Licens 